\title{
Study of the Specifics of Family Relations in Socially Vulnerable
}

\section{Families}

\section{Sukhova EV* \\ Department of labour Economics and personnel management, State Economic University, Russia}

*Corresponding author: Elena V Sukhova, Department of labour Economics and personnel management, State Economic University, Samara, Sovetskoy Armii Street, 141, Russia, E-mail:

\section{Research Article}

Volume 3 Issue 2

Received Date: February 13, 2018

Published Date: March 07, 2018 Sukhova12@yandex.ru

\section{Abstract}

Family difficulties in vulnerable families, lead to the anger of its members affect family interactions and parenting. Improper upbringing of children in socially vulnerable families can lead to marginalization of society and development of social complications. In order to provide social assistance and protection to members of socially vulnerable families, it is necessary to clearly represent the parameters by which these families differ from normative families. The study of relationships in socially vulnerable families and comparison with normative families was conducted. This article presents the peculiarities of interaction between members of socially vulnerable families and differences from normative families.

Keywords: Specifics of family relations; Socially vulnerable families; Social Assistance

\section{Introduction}

There are groups of the population, which are commonly referred to in the literature as "social slab", "socially vulnerable" "depriving" (another Eden"), and "Marginal". Different authors define these groups in different ways. But the term "socially vulnerable groups" unites these concepts, because these groups need social support to solve their own problems.

When there was a Union of Soviet Socialist Republics, the system of social protection was developed. This system includes the right of everyone to work, providing a pension for the stars of state regulation of prices for basic goods, free education, medication best help, free access to sports and various circles. They are usually functional in "Houses of pioneers".
In the modern social and economic conditions "Social protection" means the policies of the state and regions, which aims to ensure the satisfactory existence of groups, who without support will not be able to survive and exist [1]. Guarantees for work and education are reflected in the Constitution of the Russian Federation. At the same time, social and economic conditions have changed in our country, market relations are forming in the sphere of labor and education, and production relations of a new type are developing [2]. People of wage labor in the vast majority are in a state of poverty or even poverty [3]. In modern conditions support of socially unprotected groups of the population includes various benefits, allowances, payments, at minimum social guarantees in work, education and leisure. Socially unprotected segments of the population may not be able to solve everyday problems. Unemployment, poverty, low social and material levels, psychological discomfort lead to 


\section{Psychology \& Psychological Research International Journal}

stress, disrupt interaction with members of society and in the family.

A family is a group that meets the needs of its members [4]. The family plays a crucial role in the process of formation and development of personality [5]. In society there are social and cultural norms - patterns of behavior, models of behavior in standard situations. In the process of family education, a person learns specific behaviors that allow him / her not to develop new solutions, but to follow the pattern learned in his / her family [6]. In every family there are family rituals, with examples behavior in various living situations. It is important that they comply with the social and cultural norms of society.

Families in which family members are subject to family standards of conduct, engage in the activities entrusted to them, participate in overcoming various kinds of family difficulties, are harmonious [7]. Families that do not meet the basic needs of family members do not realize the basic tasks specific to each stage of the life cycle are disharmonious [8]. In such families various aspects of family functioning are broken. In disharmonious families dominated by relations of power and subordination; emotional dependence, neglect of family responsibilities; lack of cooperation, partnership, mutual aid, inequality, coercion.

\section{What are the Family Difficulties in Socially Vulnerable Families?}

Income below the subsistence level is a family difficulty. Abuse of alcohol by a father or mother is also a family difficulty. Family difficulty increases significantly when alcohol is abused by both the father and the mother. Being in prison for a family member is undoubtedly a family difficulty, as problems of employment, alcohol abuse and drug use arises in the future. Living in a communal apartment is a difficult for the family, as other residents of the communal apartment can abuse alcohol, drugs, resort to physical violence, profanity.

In order to prevent the process of marginalization, the development of social complications, it is necessary to clearly represent the peculiarities of life of people from socially vulnerable groups, their perception of life difficulties, attitude to life difficulties. Life's difficulties can lead to bitterness; desire to retaliate against other members of society for their plight and poverty. Given that many people in the socially vulnerable category were previously in prison, or with pulmonary tuberculosis, this makes them really dangerous. Therefore, the process of raising children in socially vulnerable families is not only a pedagogical, but also a social problem. After all, we are talking about the future active members of society, the development of cultural and social norms of society.

In the literature available to us we have not found results of studying of family relations in socially unprotected families, the description of family difficulties and problems, specifics of family interaction. For the working hypothesis it was assumed that in socially vulnerable family's disturbed family interaction and the process of raising children.

The aim of the study was to study the specifics of family interaction in socially vulnerable families.

\section{Method}

R. H. Moos have developed an original method of "family Environmental Skale" (FES). It is intended for studying of family relations, social climate of a family, features of family functioning. The main attention is paid to the measurement and description of: a) relations between family members (indicators of relations), B) directions of personal growth, which in the family is given special importance (indicators of personal growth), C) the basic organizational structure of the family (indicators that control the family system).

Reply can any member of the family, it describes the institutions, rules of behavior in this family. The Respondent is offered several answers to the questions relating to a certain scale, for example, conflict. The Respondent chooses the option that most accurately characterizes the relationship in his family. Statements are formulated so "in our family it is accepted...". He answers questions about what behavior is accepted in their family in certain situations, about the social and family climate. The climate of the family is the rules of behavior that have developed in the family and that affect the relationship in it. Some family rules are set openly, others are hidden, and they are derived from recurring situations that occur in the family. Rules of conduct in the family show the admissibility and inadmissibility of certain actions, are an element of family ideology. It must comply with the social and cultural norms of society.

Each answer option has an equivalent in points. Then the answers are summed up and the indicator is obtained on a specific scale, for example, conflict. In processing the data for each scale, an indicator was calculated by adding together the responses for all the scale items. The result was a family profile. First, with the help of this technique, 


\section{Psychology \& Psychological Research International Journal}

100 American families were examined, which were taken as the standard of the American family. Was well established family profile. To study the family climate in a single family, a survey of one of the family members is conducted, the family profile of the family is built and compared with the normative family profile (according to 100 standard families), using standard statistical techniques. Identify the scale on which this particular family is different from the norm.

This test was translated into Russian and adapted by S. Yu Kupriyanov in 1985 [9]. He called it "the Scale of the family environment."

The questionnaire contains 90 claims, in the form of responses a Respondent needs to make a note about which of the following statements is correct in relation to his family as a whole and not with respect to certain of its members. Family environment scale include ten scales, each of which is represented by ten points.

Indicators of the relationship between family members

1. Cohesion. The extent to which family members care for each other, help each other; expressed feelings of belonging to the family.

2. Expressivity. To what extent are families allowed to act openly and Express their feelings.

3. Conflictness. To what extent is the open expression of anger, aggression and conflict relations generally characteristic of the family?

B. Indicators of personal growth.

4. Independence. The extent to which family members are encouraged to self-discovery, independence and autonomy in the deliberation of issues and decisionmaking.

5. Focus on achievements. The extent to which different types of activities (studies, work, etc.) in the family give a character of achievement and competition.

6. Intellectual and cultural orientation. The extent to which family members are active in the social, intellectual, cultural and political spheres.

7. Orientation to active rest. As far as the family is characterized by outdoor activities and sports.

8. Moral and ethical aspects. The degree of family respect for ethical and moral values and provisions. Basic organizational structure of the family.

9. Organization. The importance for the family of order and organization (structuring of family activities, financial planning, clarity and certainty of family rules and responsibilities).
10. Control. Degree of hierarchy of the family organization, rigidity of family rules and procedures, control by family members of each other.

SY. Kupriyanov examined using these methodology 100 standard Soviet families (a total of 276 healthy subjects), none of whose members were not ill-defined Neuropsychiatric, psychosomatic or serious, chronic somatic diseases. The families had two to five members. All families had children, their average age was 14.3 yea 2.7 years. These families were regarded as the standard Soviet family in terms of life, education, lifestyle, social status and material level. One of the family members' answers questions, characterizes the social climate of the whole family and peculiarities of family interaction of all family members. The indicator for each scale is summarized. These 100 Soviet families were processed and developed a family profile of the standard Soviet families, which was adopted for the normative.

It is with this normative profile that the indicators of specific families under study are compared. With the help of this technique, 30 families were examined. Questions about family interaction met 15 men, average age 41 , $2 \pm 3.6$ years and 15 women, average age $42.4 \pm 3.5$ years, residents of large industrial city "Samara". Examined at the time of the study were formed as individuals, had certain habits, views on life, life experience, the current specifics of family interaction. They responded to questions about what behaviour in a given standard situation was accepted in their family, and how they characterized their family. Then the indicators for individual scales were summarized and compared with the indicators of the normative profile of standard families. Generally accepted statistical methods were applied [10].

Members of 30 families with low social and economic status, members of socially vulnerable families were examined. Some of them had previously been in prison; some had abused alcohol and smoked for more than 10 years. Not all families lived in separate apartments, some lived in communal apartments. Each family had a member with chronic pulmonary tuberculosis, a disabled person for the disease, who could not work and received a disability pension.

Members of these socially vulnerable families answered questions about the order in their families and the family climate. Indicators for individual scales were summarized and built a family profile of socially vulnerable families. 


\section{Psychology \& Psychological Research International Journal}

Then this profile was compared with the profile of the normative family by statistical methods. Statistically significant differences were revealed.

\section{Results}

The social and economic characteristics of the examined families are presented in table 1.

\begin{tabular}{|c|c|c|c|c|}
\hline An indicator & $\begin{array}{c}\text { The Absolute } \\
\text { number of males }\end{array}$ & \% males & $\begin{array}{c}\text { The Absolute number } \\
\text { of women }\end{array}$ & \% of women \\
\hline Secondary education & 6 & 40.0 & 5 & 33.3 \\
\hline Secondary special education & 9 & 60.0 & 9 & 60,0 \\
\hline Alcohol abuse & 8 & 53.3 & 2 & 13.3 \\
\hline Smoking more than 10 years & 15 & 100.0 & 7 & 46.6 \\
\hline Accommodation in a communal apartment & 3 & 20.0 & 5 & 33.3 \\
\hline $\begin{array}{c}\text { Accommodation in a private house without } \\
\text { amenities }\end{array}$ & 4 & 26.6 & 3 & 20.0 \\
\hline $\begin{array}{c}\text { Accommodation in a separate apartment with } \\
\text { amenities }\end{array}$ & 7 & 46.6 & 7 & 46.6 \\
\hline The lack of livelihood & 8 & 53.3 & 7 & 46.6 \\
\hline Income is below the subsistence level & 6 & 40.0 & 8 & 53.3 \\
\hline Stay in prison & 7 & 46.6 & 3 & 20.0 \\
\hline
\end{tabular}

Table 1: Social and economic characteristics of the surveyed families.

Thus, it is evident from table 1 that the families surveyed did indeed have low social and economic status. The analysis of the social environment Scale test took into account the obtained data on the socio - economic status.
The results of the survey to the specifics of family relationships are presented in table 2 .

\begin{tabular}{|c|c|c|c|c|c|c|}
\hline $\mathbf{N}$ & Scale & \multicolumn{2}{|c|}{ findings $(\mathbf{n}=\mathbf{3 0})$} & of normative Data for the family $(\mathbf{n = 1 0 0}(\mathbf{n = 1 0 0})$ & $\mathbf{T}$ \\
\hline & & $\mathrm{M}$ & $\mathrm{M}$ & $\mathrm{M}$ & $\mathrm{m}$ & \\
\hline 1 & Cohesion & 6.21 & 0.26 & 6.45 & 0.14 & 0.80 \\
\hline 2 & Expressivity & 6.46 & 0.16 & 6.18 & 0.18 & 1.12 \\
\hline 3 & Conflict & 3.69 & 0.11 & 3.20 & 0.16 & 1.60 \\
\hline 4 & Independence & 5.12 & 0.25 & 4.35 & 0.13 & 2.56 \\
\hline 5 & Orientation to achievement of & 6.27 & 0.13 & 5.46 & 0.14 & 2.76 \\
\hline 6 & Intellectual and cultural orientation & 5.63 & 0.23 & 6.08 & 0.14 & 1.50 \\
\hline 7 & Orientation to leisure & 4.92 & 0.25 & 4.37 & 0.15 & 1.83 \\
\hline 8 & Moral aspects & 5.25 & 0.25 & 5.72 & 0.11 & 1.88 \\
\hline 9 & Organization & 4.71 & 0.26 & 5.13 & 0.16 & 1.40 \\
\hline 10 & Control & 4.02 & 0.24 & 3.39 & 0.13 & 2.10 \\
\hline
\end{tabular}

Table 2: The specifics of family relations in families with low socio - economic status.

As can be seen from table 2, there are differences in normative families and in socially vulnerable families. They had significantly higher orientation towards achievement, independence, conflict, and focus on active rest, control. Compared with normative families, the moral and moral aspects are significantly lower, the intellectual and cultural orientation, cohesion and organization are unreliably lower.

\section{Discussion}

The indicator "cohesion" describes the extent to which family members care about each other, help each other. The indicator shows how satisfied the needs of family members in sympathy, respect, recognition, emotional support, psychological protection. It characterizes the emotional stability of family members. "Cohesion" is an 


\section{Psychology \& Psychological Research International Journal}

emotional acceptance by family members of each other. The cohesion of the examined families is lower than in the normative families. $\mathrm{T}=0.80$ allows to speak about the tendency to smaller cohesion of members of socially unprotected families, about the tendency to emotional detachment, inconsistency of behavior, indifference to each other.

When providing social assistance, benefits, benefits, it is necessary to provide members of socially vulnerable families with emotional support, a sense of psychological protection, respect, and sympathy.

In addition to material support, emotional support is needed.

"Expressiveness" describes the extent to which the family is allowed to act openly and Express their feelings. Conflict behavior can occur in a latent form: a demonstrative silence; a boycott of the interaction; the coldness in a relationship. Conflict can be in an open form: verbal abuse; demonstrative actions (slamming the door, smashing dishes, knocking his fist on the table), insult by physical actions. $\mathrm{T}=1.12$ indicates an open form of conflict behavior in socially vulnerable families. It can be physical and verbal abuse. If we consider that some of the members of the examined families were previously in prison, then such behavior can be dangerous. Members of socially vulnerable families should be informed in advance of where they can go in the event of violence and what specific assistance they can receive. It should be borne in mind that persons experiencing violence by family members are often afraid to contact the police. Therefore, they need to give a helpline. The Bureau of medical and social expertise, where the definition of disability is carried out, has lawyers. They protect the rights of persons with disabilities. Children in cases of violence should contact the teacher at school. Then the teacher will apply to law enforcement agencies.

In vulnerable families, significantly higher rate of conflict $(M=3,69 \mathrm{~m}=0,11$, normative $M=3,20 \mathrm{~m}=0,16$, $\mathrm{T}$ $=1,60$ ). "Conflict" is an indicator of relations between family members. Conflict is an acute way of resolving contradictions arising in the process of interaction. It consists in countering the subjects of the conflict and is accompanied by negative emotions. The causes of family conflicts can be: lack of money, lack of food, poor living conditions, alcohol abuse, jealousy, rudeness and disrespect, verbal and physical violence. These studies have shown that all these listed causes took place in socially vulnerable families.
Analysis of the social situation of respondents showed that $20.0 \%$ of men and $33.3 \%$ of women had a room in a communal apartment, $26.6 \%$ of men and $20.0 \%$ of women had a private house without amenities. 53.3 per cent of men and 46.6 per cent of women had no means of subsistence, while 40.0 per cent of men and 53.3 per cent of women had income below the subsistence level. 53.3\% of men and $13.3 \%$ of women from socially unprotected families abused alcohol. They exerted constant psychological pressure, made the situation of family members difficult and hopeless. They were rude and abusive, they were verbal and physical abuse. Therefore, increased conflict in these families has an objective justification. Problems with housing, lack of money, alcohol abuse, rudeness were projected in family conflicts.

When providing social assistance to members of socially vulnerable families, children should remember that in such families open manifestation of conflict is encouraged, shouts, curses, verbal and physical violence are habitual. Therefore, members of such families have the same pattern of behavior. In difficult situations, they will behave the same way towards other members of society, even those who seek to help them, for example, teachers or employees of the social service. They should remember that such behavior is habitual and in no way directed at the teacher's personality. Members of such families simply do not know how to behave differently. Teachers should pay special attention to children from socially vulnerable families. To teach them the rules of behavior in society, the inadmissibility of rude and aggressive behavior. To teach the rules of behavior in society on positive examples. It should be remembered that the peremptory methods of influence on members of socially disadvantaged families is unacceptable. Should explain and give examples from life.

The indicator "Independence" is significantly higher in socially vulnerable families than in normative families $(M=5,12, m=0,25$, in normative families $M=4,35, m=$ $0,13, \mathrm{~T}=2,56$ ). Independence includes financial, professional, social, emotional aspects. The analysis of the social situation showed that socially vulnerable families have poor living conditions and low incomes. Family members abuse alcohol, exhibit verbal and physical violence against members of his family. Therefore, it is quite logical that other family members want to escape from such living conditions. They want to change their lives.

The desire for financial independence will be explained by the fact that among the respondents $53.3 \%$ of men and 


\section{Psychology \& Psychological Research International Journal}

$46.6 \%$ of women had no means of livelihood. They had income below the subsistence level of 40.0 per cent for men and 53.3 per cent for women. Members of such families have as income a disability pension of one of the family members. And the money to buy alcohol. Alcohol was abused by $53.3 \%$ of men and $13.3 \%$ of women from socially vulnerable families. All family members live on a pension and benefits to the disabled person. After all, in the examined socially unprotected families, one of the members suffered from chronic pulmonary tuberculosis. Disabled TB is in need of nourishing diet. TB treatment is free. He gets food grants. But this money his family members spend on alcohol. Therefore, the family members seek financial independence.

$40,0 \%$ of men and $33,3 \%$ of women had secondary education, $60,0 \%$ of men and $60,0 \%$ of women had special education. People with this level of education are dependent in choosing a profession. Basically it is a profession with hard physical labor. In modern social and economic conditions in our country there is unemployment. And it is even more difficult for a person who is abusing alcohol or has been in prison before to find a job. Therefore, it is logical that members of socially vulnerable families seek professional independence. They want to have a job guarantee.

The desire for emotional independence can be explained by the fact that $53.3 \%$ of the surveyed men and $13.3 \%$ of women abused alcohol. Family members are emotionally dependent on the person abusing alcohol. Such a person shows physical and verbal violence against family members. Family members are in constant fear and anxiety. Strive to become independent.

In the examined families' one of the members suffered from chronic pulmonary tuberculosis. The disease began and continued in prison in $46.6 \%$ of men and $20.0 \%$ of women. After being in prison, there are certain habits, standards of behavior. In jail strict hierarchy and brutal punishment. Family members are connected by fate with the man who was in prison. Order in the family and lifestyle change. They are reminiscent of the way and order in prison. It is difficult for family members who were not in prison to tolerate such procedures. They want independence.

This is why socially vulnerable families have different types of dependencies and family members have a genuine desire for independence. "Focus on achievement" is significantly higher in socially vulnerable families than in normative families $(M=6,27, m=0,13$, in normative families $M=5,46, m=0,14, T=2,76$ ).

Orientation on achievements shows how different activities, for example, study, work in the family give the character of achievement and competition. It is important for members of such families to have material or social equivalents of all kinds of successes. The success of a family member is constantly compared with the success of other people. In case of success, a person receives moral satisfaction, positive emotions. In socially vulnerable families, positive emotions are not important. The success is to have the material equivalent for comparison. It is important to present evidence of achievements - badges, diplomas, places of winners in various competitions. The low social and material status of members of socially vulnerable families leads to a desire for compensation. The explanation lies in the real social situation of the members of the examined families. 20.0 per cent and 33.3 per cent of women had a room in a communal flat, 53.3 per cent of men and 46.6 per cent of women did not have a means of subsistence income, 40.0 per cent of men and 53.3 per cent of women. Therefore, any activity is given a competitive shade. Family members need physical evidence that their family is no worse than the rest and its members by virtue of success and achievement. Therefore, if a student from a socially unprotected family takes part in a sports competition, it is useful to give him an icon, a diploma. This can increase his self-esteem and feel like a full member of society.

"Intellectual and cultural orientation" means selfeducation, introduction to culture - reading and visiting cultural institutions. "Intellectual and cultural orientation" in socially vulnerable families is lower than in normative families $(M=5,63, m=0,23$, in normative $M$ $=6,08, \mathrm{~m}=0,14, \mathrm{~T}=1,50$ ). It is quite understandable. As visits to the theatre, Philharmonic society requires money, and surveyed families in half of the cases had no means of livelihood. The analysis of the social situation showed that 53.3 per cent of men and 46.6 per cent of women had no means of livelihood, and that they had income below the subsistence level of 40.0 per cent of men and 53.3 per cent of women.

The Russian philosopher V. V. Rozanov noted: "only family can bring up in children the most essential parties of culture". The conditions for cultural development in the family understand each other, respect, interest and satisfaction with communication, acceptance of life values, moral guidelines. Conflict is significantly higher in the examined families. Family members are characterized 


\section{Psychology \& Psychological Research International Journal}

by an open manifestation of conflict, quarrel, shouting, swearing, violence. Children from such families do not have cultural and moral standards. They do not lay down the cultural and moral norms of society. And in the future, without such norms, they will not be able to pass them to their future children.

"Active recreation orientation" is significantly higher in socially vulnerable families than in normative families $(M=4,92, m=0,25$, in normative families $M=4,37, m=$ $0,15, T=1,83$ ). This seems somewhat illogical, as the activities require funds, on the duffle, gym, sports equipment. In normative families an active holiday is not given much importance, even though the members has means for sports. In the examined families, members abused alcohol, in half of cases had no means of subsistence, did not work. The results of the study showed that $53.3 \%$ of men and $46.6 \%$ of women had no means of livelihood, $40.0 \%$ of men and $53.3 \%$ of women from the examined families had income below the subsistence level. Alcohol was abused by $53.3 \%$ of men and $13.3 \%$ of women. How is it possible in these circumstances to explain an increased craving for sports?

Original technique of "family Environmental Skale", developed by R. N. Moos, under the orientation to active means active rest and sport.

With the members of the surveyed families was conducted the supplementary survey. The question was clarified as to what exactly they meant by the term "active rest". Under the rest of the respondents understood the use of alcoholic beverages in the nature. "Rest "was used as a synonym for "Drinking". Rest after the labors socially acceptable, alcohol is frowned upon by society. Replacing the concepts of substitutes for socially unapproved behavior is socially acceptable. From the social characteristics of the members of the surveyed families it follows that $53.3 \%$ of men and $13.3 \%$ of women abused alcohol. Therefore, it becomes clear a high indicator of orientation to outdoor activities.

From the survey results it becomes clear the feature of the initiation to sport of children from socially disadvantaged families. Free access to sports sections, assistance in purchasing sports uniforms can bring children to the gym. Skilful use of the increased desire for independence and various achievements can lead to serious sports. It is important for the coach to act not only as a mentor, but also as a tutor, to give examples of their own overcoming difficulties and achievements. The coach can become a standard of masculinity, restraint, selfcontrol, a model for copying behavior. Because there are no such standards in families.

The indicator "Moral aspects" shows the degree of family respect for ethical and moral values. The indicator is significantly lower in socially unprotected families than in normative families $(M=5,25, m=0,25$, in normative families $M=5,72, m=0,11, T=1,88$ ). The essence of moral education is to turn moral ideas into norms and rules of conduct. It is necessary to form norms and rules of behavior in the society corresponding to moral norms of society in the case of younger family members. The child repeats the actions and actions of people around him, especially members of his family. If moral principles, ideals, norms of behavior, moral assessments are not supported by examples, then this leads to the development of cynicism. The analysis of the social situation of the members of the surveyed families showed that $53.3 \%$ of men and $13.3 \%$ of women abused alcohol; $100.0 \%$ of men and $46.6 \%$ of women smoked more than 10 years; $46.6 \%$ of men and $20.0 \%$ of women were in prison. The lifestyle of adult family members did not meet the moral requirements and norms of society. Therefore, there is a high probability that children from such families will also not have moral norms and rules in the future and will not follow the rules of morality in life.

Teachers, social educators, social psychologists need to pay special attention to the formation of moral norms in children from socially vulnerable families. It should be borne in mind that children in their families receive completely opposite examples of behaviour. Every child needs individual work. At the same time, an adult should have authority in the eyes of the child; his behavior should fully comply with the moral, social and cultural norms of behavior in society. Such work is necessary to prevent the marginalization of society.

The indicator "organization" describes how important order and organization are for the family. It involves structuring family activities, financial planning, clarity and certainty of family rules and responsibilities. The family includes a large number of relationships and interrelations. In their formation, the individual and personal characteristics of family members, the nature of the social environment, cultural norms, customs and traditions, and the social and economic conditions of the family are important. All of these relationships must be properly organized in order to successfully fulfill the functions of the family. 


\section{Psychology \& Psychological Research International Journal}

The indicator of "organization" in socially vulnerable families is lower than in normative families $(M=4,17, m=$ 0,26 , in normative families $M=5,13, m=0,16, T=1,40$ ). An explanation can be found in the indicators of the social status of family members. $53.3 \%$ of men and $13.3 \%$ of women had abused alcohol, $100.0 \%$ of men and $46.6 \%$ of women had smoked for more than 10 years, $53.3 \%$ of men and $46.6 \%$ of women had no means of livelihood, $40.0 \%$ of men and $53.3 \%$ of women had income below the subsistence level. The absence of stable family income, spending of scarce funds on alcohol hinders the organization of family orders and traditions. In the absence of money, it is impossible to build family plans. The problem is that children from such families have no idea of the distribution of family roles and responsibilities, the distribution of responsibilities in the family. They will not be able to organize family order in their future lives. Every family interviewed had children. We can confidently say that without a practical example in their lives, they will not be able to organize order in their future family.

The indicator "control" characterizes the degree of hierarchy of the family organization, control of family members of each other. The indicator "control" is significantly higher in socially vulnerable families than in normative families $(M=4,02, m=0,24$, in normative families $M=3,39, m=0,13, T=2,10$ ). The family includes persons of different sex, age, build, temperament. Interaction of family members is subject to certain laws, stereotypes of interaction, rules, ways of communication. In each family, there are rules, what actions and in what sequence family members should do when they enter into relationships with each other and with other people. The study showed that $46.6 \%$ of men and $20.0 \%$ of women from the surveyed families were previously in prison. In prison there are strict orders of relations, the hierarchy of relations is observed, strict control. All are divided into certain castes, depending on the crime committed. The transition from one caste to another is not valid. There is a senior who solves all disputes and resolves contradictions. Certain rules and standards of conduct in prison have been developed. They must be strictly adhered to. Meals and other household treatments are made in accordance with caste. Violation of order is severely punished by the prisoners themselves in accordance with the order of the senior in this prison from among the prisoners. It monitors compliance with the code of conduct for prisoners in prison. And such strict and cruel orders in the future are transferred to the family. Family members must also submit implicitly to the head of the family, to comply with all his requirements and orders. Disobeying is severely punished. Under control are all contacts of family members and all their actions. If the head of the family is unhappy with any action, the family member may be severely punished. If children from such families complain about their lives to teachers at school, they will be severely punished at home. This also applies to women. They can also be subjected to violence. They're afraid to protect their children. They are afraid to go to the psychologist, in confidence, to the guardianship.

Strict and strict control, regulation of behavior increase tensions between family members. Increased conflict, strict control of behavior provoke the desire for independence, reduce moral standards. Children from socially unprotected families are not trained to take responsibility for their actions, cannot make their own decisions. They habitually driven behavior, submission to authority. In the future, if authority forces them to commit unlawful acts, they will do so. Moreover, they have not formed moral norms, reduced integrity of the individual. In these circumstances, it is especially important that the teacher in the school became an authority. It needs to instill the moral standards of society. It may indirectly identify family violence against the child and to take measures, for example, to apply to the guardianship and guardianship.

\section{Conclusion}

Analysis of the results of the conducted research has allowed revealing differences of the socially vulnerable families from the normative Russian families. In all the surveyed families there were problems: poor housing conditions, low material level, alcohol abuse, long-term Smoking, one of the family members earlier in jail, chronic illness of a family member. In families, there is indifference of family members to each other, verbal and physical violence, rudeness, strict control over behavior and contacts, do not form the moral norms adopted in society. This leads to an increased desire for independence, the desire to escape from the family. But women and children are often afraid to seek help, afraid to be punished by the head of the family. Therefore, it is useful for school teachers to get acquainted with the results of studying relationships in socially vulnerable families. They should pay special attention to children from such families. It is necessary to form moral rules and norms in children from socially vulnerable families. This is the prevention of delinquency in the future by children from such families. Surveys of violence against the child 


\section{Psychology \& Psychological Research International Journal}

should be conducted with constant sensitivity and appropriate measures should be taken.

In addition, it is useful at school to have a stand where the child's actions in the case of violence should be presented in the form of an algorithm. They must be understandable. The child must be confident that, in the event of violence, he or she will be assisted and supported. He should not be afraid to ask for help. There are departments of social protection of the population. They provide assistance of all kinds - and in the acquisition of clothing, and the purchase of food, and in obtaining permits for treatment. Often people just do not have information about how much state aid they can get and what documents they need to submit for assistance. There are district social welfare centres in each district. A person should have information about whom and in what cases assistance is provided. It is advisable to present this information in the form of an algorithm and develop instructions for possible assistance. These brochures can be given to people who need social assistance. For example, a teacher can give such a brochure to a schoolboy's mother. Previously, he tactfully and delicately finds out the living conditions and life of the student. With such a brochure, a woman could decide for herself whether she should contact the social protection authorities. In addition, there are correction classes in ordinary schools. There are also specialized schools. For example, for children with mental retardation. Special programmes have been developed. There are teachers who have had special training. In one class fewer children. This allows the child to spend more time. These opportunities should also be made more widely available.

It is important for children from socially vulnerable families to be accustomed to sports. They should be assisted in the acquisition of sports uniforms and equipment. Such funds are available from the school Fund. There are music and art schools where children are taught music and drawing. It is clear that the child will not be able to buy a musical instrument or paint with brushes. But he can help in this school Fund. In this case, the child will be isolated from his family members, fall into a healthy psychological atmosphere. It is important that children take part in school excursions and hikes. They get free hot meals at school. The school assists in the acquisition of school uniforms and textbooks. Therefore, the teacher must be a real authority. It is on him, his moral criteria and norms should be oriented to the child all his life. At the same time, interaction with a child from such families is difficult. They have increased conflict, the usual shouting, swearing, insults. Patience and tact should be shown.

Teachers should also have information about various charities. They can bring this information to members of socially vulnerable families.

\section{Summary}

1. The following difficulties have been identified in socially vulnerable families: lack or lack of means of livelihood, alcohol abuse, poor living conditions, detention of family members, chronic illness of a family member.

2. Family relationships in socially unprotected families have been disrupted. Roughness, verbal and physical violence, strict control over behavior and contacts are common.

3. The children have not formed the moral norms of behavior and skills of the organization of family roles.

4. Because of fear of punishment, women and children are afraid to talk about violence. Therefore, it is advisable in each school to have a stand, which is presented in the form of an algorithm of action of the child in case of violence. He should be sure that the school will receive help and support.

\section{References}

1. Lelekov VA, Kosheleva EN (2007) On prevention of juvenile delinquency. Sociological research 12: 87-95.

2. Povchednay FV, Llebedeva IV (2015) Family in the context of the problems of childhood and adolescence. Modern problems of science and education 3: 376.

3. Karabanova OA (2010) Disharmonically parent-child relationship as a risk factor for deviant behavior of the personality. Protect me 4:46-51

4. Elise Boulding (1979) Children's Rights and the Wheel of Life. New Bruns- wick, NJ, USA, pp: 89.

5. James A, Prout A (1997) Constructing and Reconstructing Childhood: Contem- porary Issues in the Sociological Study of Childhood. Falmer Press (A member of the Taylor \& Francis Group). London: Washington, DC, pp: 256.

6. O'Hare W, Mather M, Dupuis G, Kenneth CL, Vicki LL, et al. (2012) Analyzing State Differences in Child 


\section{Psychology \& Psychological Research International Journal}

Well-Being among US states. Foundation for Child Development. 401-431.

7. Suvorova OV, Vasilyeva EN (2004) Emotional and social development of the senior preschool child depending on the mother's acceptance. Bulletin of Nizhny Novgorod state University. Series Social Sciences 1(3): 12-26.

8. Zemeleva ZA (2011) Aggressive behavior of teenagers and parents personality. Psychological science and education 4: 2273.
9. Kupryanov SU (1985) The Role of family factors in the formulation of Neuro - psychic mechanism of the pathogenesis of bronchial asthma and their correction methods of family therapy.

10. Arutunova AU, Eremina US (2013) A social behavior of a person: definition, essence. Economic and humanitarian research of regions 5: 12 . 